\title{
Torsion of the Spermatic Cord: Clinical and Therapeutic Aspects in the Region of Thies (Senegal)
}

\section{Yoro Diallo*, Johanitha Lionnelle Elonme Alissoutin, Saint Charles Kouka, Modou Diop N'diaye, Mehdi Daher, Ramatoulaye Ly, Cheikh Diop, Seydou Diaw, Cheickna Sylla}

Department of Urology, Faculty of Health Sciences, University of Thies, Thies, Senegal

Email: *yorodiallo@hotmail.com

How to cite this paper: Diallo, Y., Alissoutin, J.L.E., Kouka, S.C., N'diaye, M.D., Daher, M., Ly, R., Diop, C., Diaw, S. and Sylla, C. (2019) Torsion of the Spermatic Cord: Clinical and Therapeutic Aspects in the Region of Thies (Senegal). Advances in Reproductive Sciences, 7, 60-70. https://doi.org/10.4236/arsci.2019.73008

Received: April 29, 2019

Accepted: June 8, 2019

Published: June 11, 2019

Copyright () 2019 by author(s) and Scientific Research Publishing Inc. This work is licensed under the Creative Commons Attribution International License (CC BY 4.0).

http://creativecommons.org/licenses/by/4.0/

\begin{abstract}
Introduction: The purpose of this work is to evaluate the epidemiological, clinical and therapeutic aspects of spermatic cord in our context. Patients and Methods: This is a retrospective study over a period of 4 years from January 1, 2014 to June 30, 2018. Results: We collected 55 cases divided into 26 cases, $44.27 \%$ for the Thies Regional Hospital, $21 \%$ or $38.18 \%$ for the Mbour EPS and 8 cases representing 14.55\% for the Saint Jean de Dieu Hospital. We found an average age of 20.03 years with extremes of 4 years and 56 years. In 28 patients or $50 \%$ of cases, we found no particular pathological history, while in 4 patients or $7.14 \%$, we found a notion of recurrent ipsilateral testicular pain. We recorded $67.27 \%(\mathrm{n}=37)$ of the cases received for testicular pain; 15 patients or $27.27 \%$ presented a large painful pouch. Two patients $(3.64 \%)$ were received for inguinal swelling and 1 patient $(1.82 \%)$ presented testicular atrophy. The average consultation time is 16.9 hours with extremes of 2 hours and 96 hours. The torsion was in $59.61 \%$ of cases $(n=32)$ located on the right versus $40.38 \%(n=22)$ on the left. There was no bilateral form. The pick-up time was 3 hours with extremes of $1 \mathrm{~h}$ to $24 \mathrm{~h}$. All patients benefited from an exploratory scrotomy. We found a total of 22 patients or $40 \%$ of cases with ischemic testis, 8 cases or $14.55 \%$ of patients with necrotic testis and 2 cases or $3.64 \%$ where the testis was normal. Orchidopexy was performed in 46 patients or $83.63 \%$ and orchiectomy in 9 patients. Conclusion: Care is urgent. There is a need for better awareness of the population and the medical staff for the early diagnosis.
\end{abstract}

\section{Keywords}

Spermatic Cord Torsion, Young Subject, Exploratory Scrotomy, Orchiectomy 


\section{Introduction}

The twisting of the spermatic cord is defined as strangulation of the spermatic cord around its vascular axis leading to ischemia or even testicular necrosis. It is an andrological emergency. Its incidence is estimated in France, at one per 4000 males younger than 25 years [1]. It represents $24 \%$ of andrological frequencies for Valla et al. [2] and 29.2\% for Cavusoglu et al. [3]. In Benin, spermatic cord torsion represents $17 \%$ of andrological emergencies [4]. In Cameroon, they have a frequency of $11.34 \%$ of acute scrotal disease in children [5].

It is a pathology of the young subject about $65 \%$ of cases occurring at puberty [6].

The preservation or not of the testicle depends essentially on the duration of evolution, the degree of the spermatic torsion, and the time of management [7]. In our context, the management of twists of the spermatic cord is difficult. Among other things, the weight of taboos in society, ignorance of the urgency of care, and the difficulties of rapid reference lead to a significant delay in diagnosis and treatment [8]. The medico-legal aspect of the management of twists of the spermatic cord takes an increasingly important place in the everyday life of the practitioners.

The aim of this work is to study the clinical and therapeutic aspects of spermatic cord torsion in the Thies region.

\section{Patients and Methods}

This is a multicenter retrospective study over a period of four (4) years, from May 31, 2014 to June 1, 2018. The study involved all patients with sperm cord torsion and received in the structures. sanitary facilities in the Thiès region, including the Regional Hospital Center, the Saint Jean de Dieu Hospital and the Mbour Public Health Facility.

Inclusion criteria: All patients with spermatic cord torsion confirmed by exploratory scrotomy and managed in these reference services. Criteria for non-inclusion: Patients with incomplete files were not included in the study.

The parameters studied were: marital status, medico-surgical antecedents, mode of admission, reasons for consultation or hospitalization, delay of consultation of support, the circumstances of occurrence, the data of the clinical examination, the balance sheet urgently requested, the treatment established in emergency, the future of the patient and the follow-up of the patient.

The data was entered on a computer and analyzed with the Epi info 3.5.1 software (version 7.2.2.6) in its French version, and the Excel software. The anonymity of the patients has been respected.

\section{Results}

We collected 55 cases divided into 26 cases, $44.27 \%$ for the Thies Regional Hospital, $21 \%$ or $38.18 \%$ for the Mbour EPS and 8 cases representing $14.55 \%$ for the Saint Jean de Dieu Hospital. The mean age of patients was 20.03 years (range, 4 to 56 years), median was 18 years, mode was 16 years (Figure 1 ). 


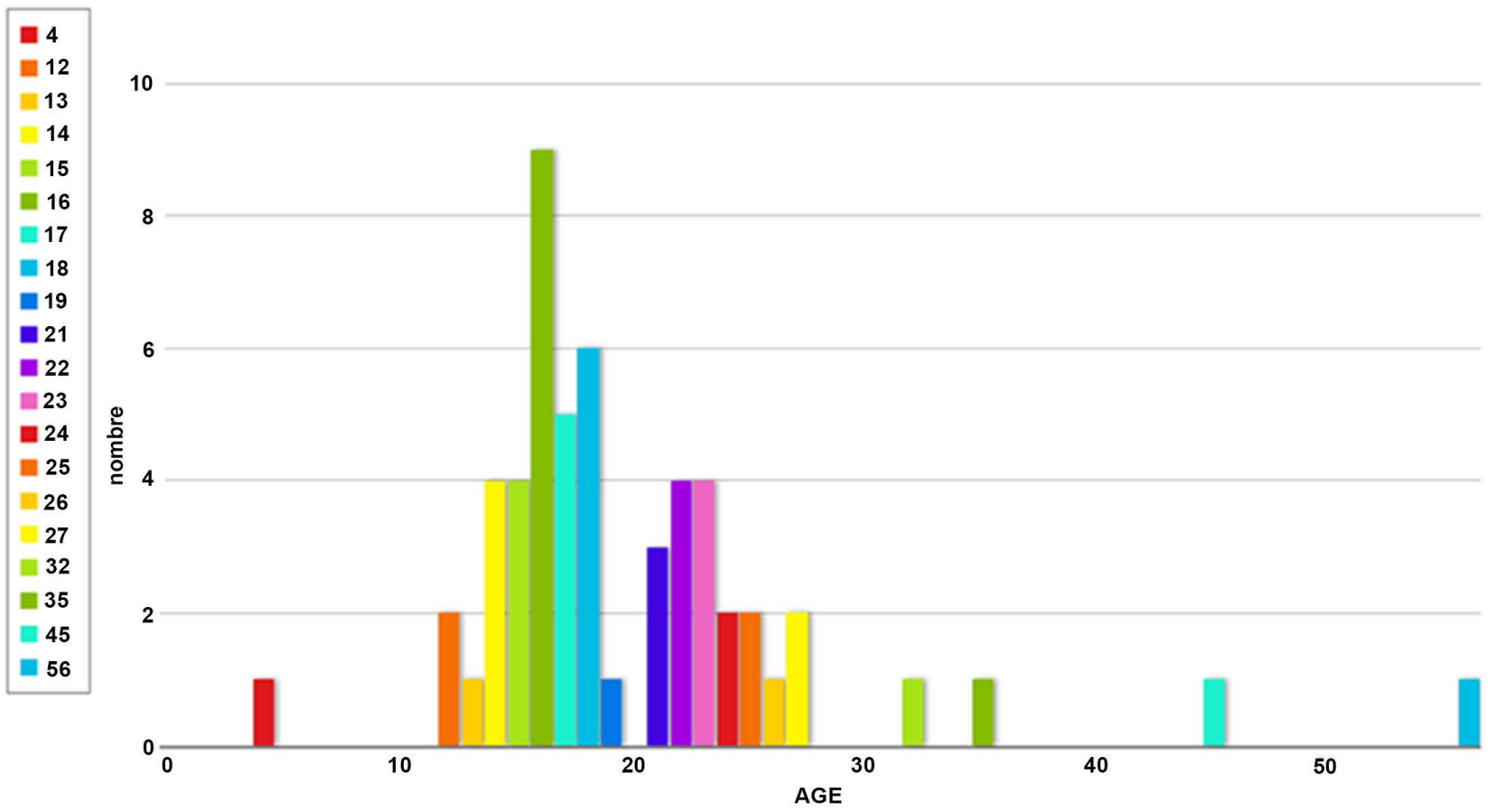

Figure 1. Distribution of cases by age.

In 28 patients or $50 \%$ of cases, we found no particular pathological history, while in 4 patients or $7.14 \%$, we found a notion of recurrent ipsilateral testicular pain. In 1 patient $(1.79 \%)$ homolateral orchidopexy on torsion of the spermatic cord was performed and 1 case of contralateral orchi-epididymitis was mentioned. In $37.5 \%(n=21)$ of the cases, the antecedents were not specified.

For the functional signs, we recorded $67.27 \%(\mathrm{n}=37)$ of the cases received for testicular pain, 15 patients or $27.27 \%$ presented a large painful pouch. Two patients (3.64\%) were received for inguinal swelling and 1 patient (1.82\% for scrotal vacuity) (Figure 2).

The average consultation time is $16.9 \mathrm{~h}$ with (extremes of $2 \mathrm{~h}$ and $96 \mathrm{~h}$ ) with a median of $6 \mathrm{~h}$. We find that 14 patients or $40 \%$ were admitted before $6 \mathrm{~h}$ of evolution, 9 patients or $25.71 \%$ between 6 and 12 h. $14.29 \%$ of the cases or 5 patients were admitted between 12 and 24 hours while 7 were admitted before 24 hours or $20 \%$ (Table 1 ).

These functional signs are associated with digestive signs in $27 \%$ or $49.09 \%$ of cases and are vomiting type in 7 patients or $12.73 \%$ of cases. In 21 patients, we did not find any associated signs.

The torsion was in $59.6 \%$ of cases $(\mathrm{n}=32)$ located on the right versus $40.4 \%$ $(\mathrm{n}=22)$ on the left. There was no bilateral form (Figure 3 ).

The Prehn maneuver was positive in $31 \%$ in 17 patients. The governor's sign was present in $71 \%$ of the cases, 39 patients and absent in 16 (29\%). Doppler ultrasonography was performed in $16(29.02 \%)$ patients.

The pickup time was 3 hours with extremes of 1 hour to 24 hours. The exploratory scrototomy was performed in all patients and objectified in all cases 
- ALGIE TESTICULAIRE INTERMITTENTE HOMOLATERALE GURE DE TORSION SPERMATIQUE HOMOLATERALE $=$ NON

In ORCHIEPIDIDYMITE CONTOLATERALE

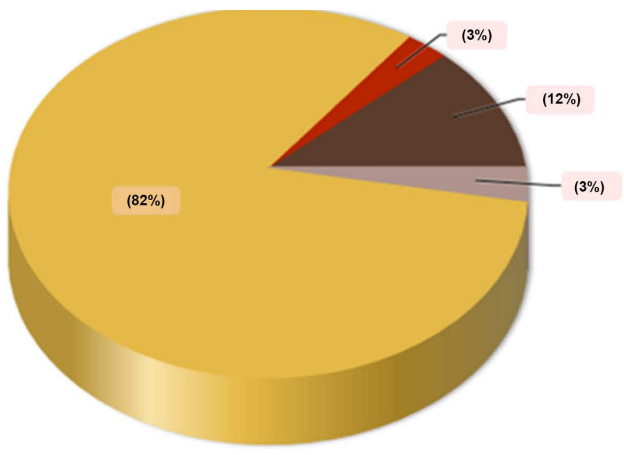

Figure 2: Distribution of cases by reason of admission.

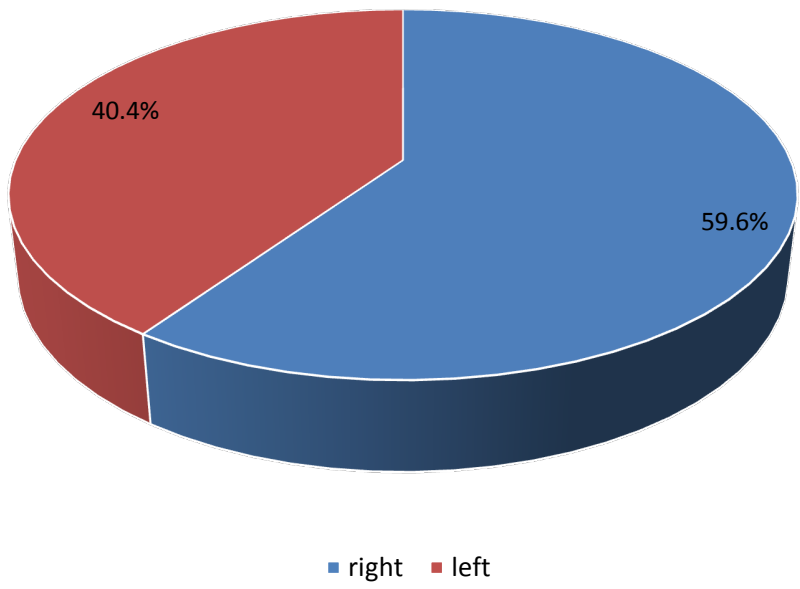

Figure 3. Distribution according to the side of the torsion.

Table 1. Distribution of cases according to the admission period.

\begin{tabular}{ccc}
\hline Admission deadline & Number & Frequency \\
\hline$[0 \mathrm{~h}-6 \mathrm{~h}[$ & 14 & 25.45 \\
{$[6 \mathrm{~h}-12 \mathrm{~h}[$} & 9 & 16.37 \\
{$[12 \mathrm{~h}-24 \mathrm{~h}[$} & 22 & 40 \\
{$[24 \mathrm{~h}$ et $\mathrm{plus}]$} & 10 & 18.18 \\
TOTAL & 55 & 100.00
\end{tabular}

the torsion of the spermatic cord. It was preceded by 3 patients or $5.45 \%$ of an external detorsion maneuver. We have 14 patients or $63.64 \%$ of the cases who had 2 turns of turn against 4 patients for 1 turn of turn. Only one patient presented 3 turns of coil in intraoperatively.

Orchidopexy was performed in 46 patients or $83.63 \%$ and orchidectomy in 9 patients (16.37\%) (Figure 4).

We found a total of 22 patients or $40 \%$ of cases with ischemic testis, 8 cases or $14.55 \%$ of cases with a necrotic testicle and 2 cases or $3.64 \%$ where the testicle had a normal appearance (Figure 5). 


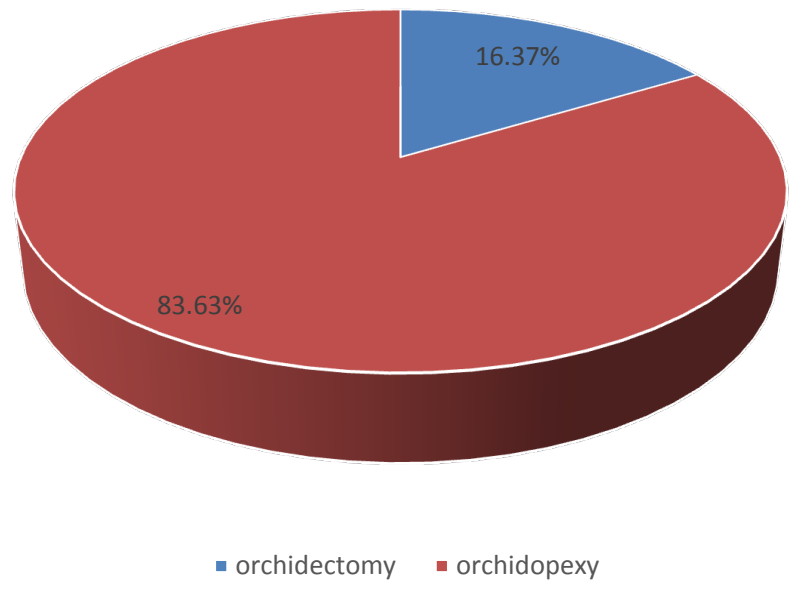

Figure 4. Distribution according to the operative gesture.

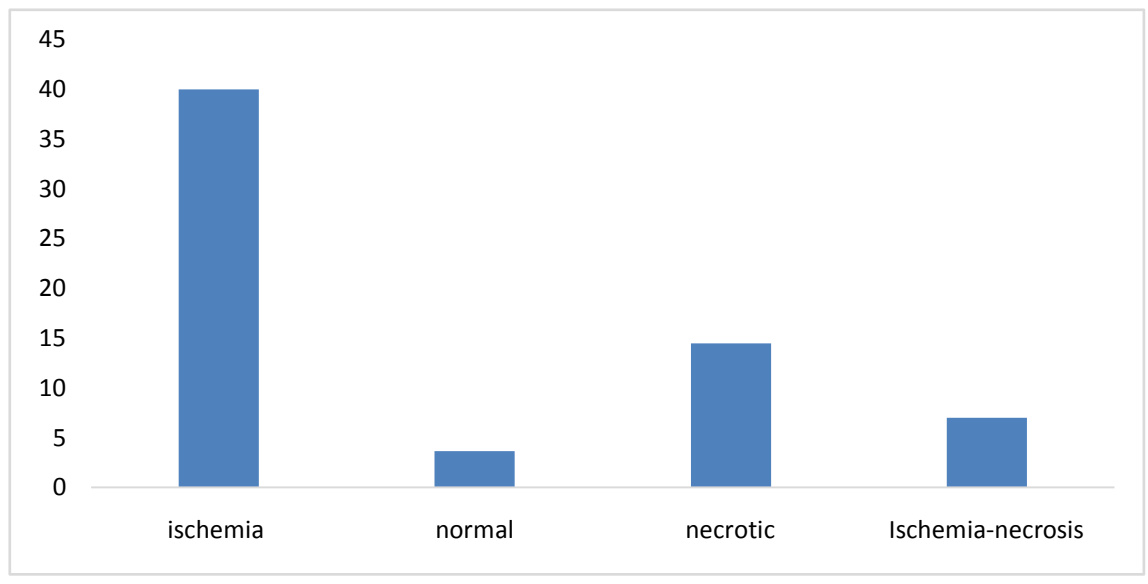

Figure 5. Distribution of cases according to the appearance of epididymo-testicular blocks.

We found 10 cases of ischemia when the admission time is less than 6 hours and 6 cases for an admission period between 6 and 12 hours. All cases of necrosis were received beyond 12 hours with 2 cases between 12 and 24 hours and 4 cases over 24 hours (Table 2).

\section{Discussion}

Twisting of the spermatic cord is one of the most common surgical emergencies in adolescents [4]. Its prevalence varies according to the authors and also according to localities. In the United States, the prevalence of twisting of the spermatic cord is estimated to be $8.6 \%$ of all urological urgencies in young people between 10 and 19 years of age [6]. According to Audenet [7], its incidence is estimated at one per 4000 men under 25 years of age.

We find two peaks of spermatic cord torsion prevalence: in newborns and adolescents around the age of 15 [9]. Zhao et al. [10] also found this bimodal 
Table 2. Distribution according to the intraoperative aspect in relation to the admission period.

\begin{tabular}{cccccc}
\hline $\begin{array}{l}\text { Intraoperative aspects of the } \\
\text { epididymo-testicular blocks }\end{array}$ & $<6 \mathrm{~h}$ & $<12 \mathrm{~h}$ & $<24 \mathrm{~h}$ & $>24 \mathrm{~h}$ & TOTAL \\
\hline Ischemia & 11 & 8 & 0 & 1 & 20 \\
Necrosis & 0 & 0 & 2 & 4 & 6 \\
Normal & 3 & 1 & 3 & 0 & 7 \\
Testicular atrophia & 0 & 0 & 0 & 2 & 35 \\
TOTAL & 14 & 9 & 5 & 7 & 2 \\
\hline
\end{tabular}

distribution around the neonatal period and around the age of 14 years. According to Even et al. [11], neonatal twists of the spermatic cord represent about $10 \%$ of torsion cases. In the same series, the author placed the median age at age $13(0.18$ - 14.97) with a peak occurring between 11 and 15 years of age [11].

Torsion is an affection of the young subject. In Africa, especially in the sub-region, we find a single peak of frequency around the pubertal period. Indeed, Sarr A. et al. [8], found an average age of 21 years. Diabate I et al. [12] found a slightly advanced age average of 26.57 years. In the case series of Hodonou et al. [13], the authors found 36\% of patients aged between 15 and 19 years. In Togo, Gnassingbé et al. [14] have, meanwhile, achieved an average age of 9 years with extremes of 7 days and 15 years. In Cameroon, the average age was 19 years [5]. These values are similar to those found in our study, which is 20.03 years old.

This demonstrates that the range between 12 and 17 years are more exposed. As has been pointed out, for most authors in our context an existence often a single peak frequency [8]. Therefore, the peak of neonatal frequency usually underlined is little mentioned.

This finding can be explained by a selection bias related to the fact that most of the children who come for emergency consultation, for a large acute painful purse, are generally received in the pediatric surgery departments and these are the older children or teenagers. who present themselves in emergency surgical services in urology.

The antecedents are a decisive element to take into account. Indeed, there may be resolving episodes of torsion, cases of anterior torsion on the contralateral side. We found $7.14 \%$ of recurrent ipsilateral testicular pain. The presence of certain malformations including cryptorchidism, which constitutes proven risk factors for torsion of the spermatic cord. For this reason, the interrogation must be well conducted to prevent spermatic torsion.

The admission period is variable in the literature and depends on several factors. In our study, the average consultation time is 16.9 hours. These results are similar, some found in the literature, including Even et al. [6] have an average delay of 19.5 hours and 17 hours, respectively.

On the other hand for Sarr A. et al. [8], the average time between onset of 
painful symptomatology and admission to emergency is 102 hours. Forty-seven patients were received after the sixth hour. Whereas for Hodonou [13], the average consultation time was 08 days.

These delays are well above the 27.5 hours found by Sessions AE et al. [15]. This long delay is explained on the one hand by the lack of information concerning the affection, which relates to the urgency of care and on the other hand the taboo phenomenon which is the object of these young people who prefer to suffer silently. Another problem is related to the diagnostic errors on the part of the health staff because of the ignorance of the affection. The distance from the reference structures must be taken into account.

The most common functional sign in the literature is acute and unilateral scrotal pain. This is the master symptom. Interrogation makes it easy to highlight and guide the diagnosis quickly. This pain is constant in most studies. Indeed, in the series of Ameh EA et al. [16], the pain was found with a frequency of $80.8 \%$. This frequency is $62 \%$ in the series of Mondet et al. [17] and $72 \%$ in the series of Ralahy FM et al. [18]. These results are consistent with those found in our study with $67.27 \%$ unilateral scrotal pain. It is a symptomatology that often pushes patients to come for emergency consultation. Moreover, it is associated with variable frequencies in the literature to other signs such as vomiting in $35.5 \%$, nausea with $67.9 \%$ of cases according to the meta-analysis of Cummings JM et al. [19].

There is no predominance of side. We note a side variability for torsion of the spermatic cord. Indeed, A. Sarr et al. [8] who found 52\% torsion cases located on the right. On the other hand for Sauvat $\mathrm{R}$ et al. [20] and Gnassingbe [14], it predominated on the left. A study conducted by Vanina et al. [21] did not show any privileged lateralization. In our series, there was a straight predominance.

At the surgical exploration, all the cases were intra-vaginal torsions compared to A. Sarr [8] who found $8.6 \%$ Supra vaginal All over 15 years old. However, the intravaginal twist of the spermatic cord is the most common form outside the neonatal period [3].

In short, no clinical sign is specific to the TCS, hence the attitude to any major painful acute to perform an exploratory scrotomy to the slightest doubt.

Echo-doppler was performed in $29.02 \%$ of our cases. However, Even et al. [6], found an infrequent recourse to ultrasound and only $77 \%$ of contributory ultrasounds.

Zini et al. [22] concluded that scrotal ultrasound could be falsely reassuring and delay management. Similarly, other authors even consider ultrasound scanning and possibly Doppler as not very contributive in and that it only delays the time of the intervention [23].

No para-clinical examination should delay its surgical management, which must be urgent in order to limit the duration of ischemia with the risk of testicular necrosis [24]. The visualization of turns is much more reliable with $99 \%$ against $76 \%$ in the series of Kalfa et al. [25]. We found in our study, an 


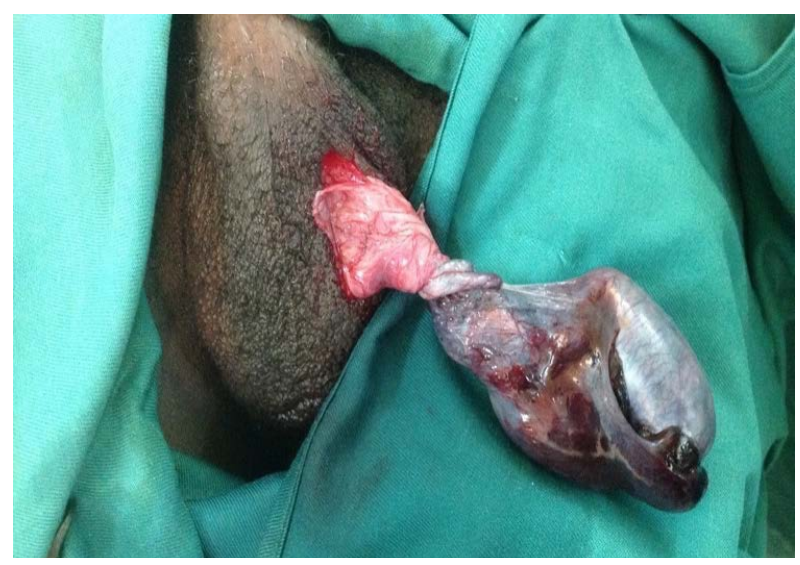

Figure 6. Spermatic cord twist with testicular necrosis.

orchidectomy rate of $16.37 \%$. This rate is low compared to that found in the literature. Indeed, A Sarr et al. [8] found 52\% of orchiectomy performed against $50 \%$ in the series Diabaté I et al. [12] and 55\% in the series of Kabore et al. [23].

On the other hand Tajchner et al. [26] reported only one case of orchiectomy for 41 cases of twisting of the spermatic cord. As for Gnassigbé et al. [14], they did not perform any orchiectomy in a series of 17 cases. Our results are similar to the rates of Zini et al. [22] who found respectively $15 \%$ and 18\%. Glabeke E et al. [9] reported $18.2 \%$ orchidectomy versus $20.3 \%$ for Even et al. [6]. Orchidectomy is performed in cases of testicular necrosis. The vitality of the epididymo-testicular block depends on the delay of management. Indeed, the overall rate of testicular preservation after torsion is $40 \%$ to $70 \%$ but we have $100 \%$ conservation before three hours, $90 \%$ before six hours and less than one in two after ten hours [19].

The trophic prognosis of the twisted testis is conditioned by the severity of the acute ischemia, itself directly dependent on the number of turns of the cord and the duration of the torsion [27] (Figure 6).

The medico-legal aspect is becoming more and more important in the day-to-day practice of practitioners and the management of scrotal pathology is a recurring complaint [28]. Tengue $\mathrm{K}$ et al. [29] showed that $74 \%$ of the complaints concerned a misdiagnosis, $48 \%$ the absence of specialized opinion and $13 \%$ the absence of scrotal exploration.

\section{Conclusion}

Twisting the spermatic cord is an andrological emergency. Early and adequate management is crucial for the preservation of testicular functions. Diagnostic delay is often linked to a lack of information and ignorance of the urgency of this condition. It is a pathology that can occur at any age but especially in the young subject. The clinical picture is easy in front of an acute and unilateral pain syndrome of a stock exchange. Paraclinical investigations are not essential. The only thing to do is the exploratory scrotomy. Its impact in our context is underestimated, which is accentuated by taboo phenomena. 


\section{Conflict of interest}

The authors declare that they have no conflict of interest

\section{The Ethics Committee}

Approved the protocol file and the study conditions concerning Torsion of the spermatic cord: Clinical and therapeutic aspects in the region of Thies (Senegal).

\section{References}

[1] Bah, O.R., Roupret, M., Guirassy, S., Diallo, A.B., Diallo, M.B. and Richard, F. (2010) Clinical Aspects and Management of the Torsion of the Spermatic Cord: Study of 27 Cases. Progrès en Urologie, 20, 527-531. https://doi.org/10.1016/j.purol.2009.12.011

[2] Valla, J.S., Steyaert, H., Colomb, F. and Ginier, C. (1998) Management of Acute Swollen Scrotum in Children. Annales de Chirurgie, 52, 1033-1037.

[3] Cavusoglu, Y.H., Karaman, A., Karaman, I., Erdogan, D., Aslan, M.K. and Varlikli, O. (2005) Acute Scrotum: Etiology and Management. The Indian Journal of Pediatrics, 72, 201-203. https://doi.org/10.1007/BF02859255

[4] Avakoudjo, J.D.G., Ouaké, H.I. and Mensah, A.D.E. (2016) Andrological Emergencies in General Surgery Service in Parakou (Benin). Uro' Andro, 1, 301-304.

[5] Mpah, E.H.M., Fouda, P.J., Sala, B.T., Eboumbou, M.E.C., Njimah, A.N., Tsiagadigui, J.C. and Berthe, H.J.G. (2012) Andrologic Emergencies in Urban Area of Cameroon: Clinical and Therapeutical Features. Basic and Clinical Andrology, 22, 223-226. https://doi.org/10.1007/s12610-012-0190-3

[6] Even, L., Abbo, O., Le Mandat, A., Lemasson, F., Carfagna, L., Soler, P., Moscovici, J., Galinier, P. and Bouali, O. (2013) Testular Torsion in Children: Factors Influencing Delayed Treatment and Orchidectomy Rate. Archives de Pédiatrie, 20, 364-368. https://doi.org/10.1016/j.arcped.2013.01.008

[7] Audenet, F. and Rouprêt, M. (2010) Torsion of the Testicular Cord: Clinical Diagnosis and Therapeutic Management. Progrès en Urologie, 20, 810-814. https://doi.org/10.1016/j.purol.2010.05.016

[8] Sarr, A., Fall, B., Mouss, B., Sow, Y., Thiam, A., Diao, B., Fall, P.A. and Diagne, B.A. (2010) Diagnostic and Therapeutic Features of Testicular Torsion in CHU Aristide-Le-Dantec of Dakar. Andrology, 20, 203-208.

https://doi.org/10.1007/s12610-010-0083-2

[9] Van Glabeke, E., Ferhi, K. and Maloum, C. (2010) Torsion of Spermatic Cord: Can We Trust a Previous Orchidopexy? A Casereport with Loss of a Single Testis with Medico-Legal Issue. Progrès en Urologie, 20, 657-659. https://doi.org/10.1016/j.purol.2010.01.009

[10] Zhao, L.C., Lautz, T.B., Meeks, J.J. and Maizels, M. (2011) Pediatric Testicular Torsion Epidemiology Using a National Database: Incidence, Risk of Orchiectomy and Possible Measures toward Improving the Quality of Care. Journal of Urology, 186, 2009-2013. https://doi.org/10.1016/j.juro.2011.07.024

[11] Trabanino, C., Even, L., Abbo, O., Mouttalib, S., Galinier, P. and Bouali, O. (2014) Torsion of the Spermatic Cord in Children: Factors Influencing the Orchidectomy Rate. Archives de Pédiatrie, 21, 886. https://doi.org/10.1016/S0929-693X(14)72146-3

[12] Diabaté, I., Ouédraogo, B. and Thiam, M. (2016) Acute Scrotal Swelling at Louga 
Regional Hospital, Senegal: Epidemiologic, Etiologic and Therapeutic Aspects. Pan African Medical Journal, 24, 214. https://doi.org/10.11604/pamj.2016.24.214.9876

[13] Hodonou, R., Soumanou, K.R. and Akpo, C. (1999) Torsion of the Spermatic Cord: Etiopathogenic, Diagnostic and Therapeutic: About 33 Cases in Cotonou. Médecine d Afrique Noire, 46, 35.

[14] Gnassingbe, K., Akakpo-Numado, G.K., Songne, G.B., Anoukoum, T., Sakiye, K.A., Kao, M. and Tekou, H. (2009) Acute Scrotum in Children. Mali Medical, 24, 31-35.

[15] Sessions, A.E., Rabinowitz, R., Hulbert, W.C., Goldstein, M.M. and Mevorach, R.A. (2003) Testicular Torsion: Direction, Degree, Duration and Disinformation. Journal of Urology, 169, 663-665. https://doi.org/10.1016/S0022-5347(05)63987-0

[16] Ameh, E.A. (1999) Incarcerated and Strangulated Inguinal Hernias in Children in Zaria, Nigeria. East African Medical Journal, 76, 499-501.

[17] Mondet, F., Chartier-Kastler, E., Yonneau, L., Bohin, D., Barrou, B. and Richard, F. (2002) Epidemiology of Urological Emergencies in a Teaching Hospital. Progrès en Urologie, 12, 437-442.

[18] Ralahy, F.M., Ramb, H., Rakototiana, F.A., et al. (2010) A Case of Extravaginal Twisting of Spermatic Cord. Archives de Pédiatrie, 17, 1448-1450. https://doi.org/10.1016/j.arcped.2010.07.006

[19] Cummings, J.M., Boullier, J.A., Sekhon, D. and Bose, K. (2002) Adult Testicular Torsion. Journal of Urology, 167, 2109-2110. https://doi.org/10.1016/S0022-5347(05)65096-3

[20] Sauvat, F., Hennequin, S., Ait Ai Slimane, M. and Gauthier, F. (2002) Age for Testicular Torsion? Archives de Pédiatrie, 9, 1226-1229.

https://doi.org/10.1016/S0929-693X(02)00112-4

[21] Vanina, E., Meyrat, B.J., Birraux, J., Vidal, I. and Sanchez, O. (2017) Diagnosis and Management of Testicular Torsion in Children. Revue Médicale Suisse, 13, 406-410.

[22] Zini, L., Mouton, D., Leroy, X., Valtille, P., Villiers, A., Lemaitre, L. and Biserte, J. (2003) Scrotal Ultrasound Should Be Decouraged If There Is Suspicion of Torsion of the Spermatic Cord ? Progrès en Urologie, 13, 440-444.

[23] Kaboré, F.A., Zango, B., Yaméogo, C., Sanou, A., Kirakoya, B. and Traoré, S.S. (2011) Torsion of the Spermatic Cord in Adults at Yalgado Ouédraogo Teaching Hospital of Ouagadougou. Andrologie, 21, 254-259. https://doi.org/10.1007/s12610-011-0151-2

[24] Galinier, P., Carfagna, L., Kern, D., Moscovici, J. and Moscovici, J. (2003) Pathological Emergencies of the External Genital Organs in the Newborn. Archives de Pédiatrie, 10, 174-178. https://doi.org/10.1016/S0929-693X(03)00004-6

[25] Kalfa, N., Veyrac, C., Lopez, M., Lopez, C., Maurel, A., Kaselas, C., et al. (2007) Multicenter Assessment of Ultrasound of the Spermatic Cord in Children with Acute Scrotum. Journal of Urology, 177, 297-301. https://doi.org/10.1016/j.juro.2006.08.128

[26] Tajchner, L., Larkin, J.O., Bourke, M.G., Waldron, R., Barry, K. and Eustace, P.W. (2009) Management of Acute Scrotum in a District General Hospital: 10-Year Experience. Scientific Word Journal, 28, 281-286. https://doi.org/10.1100/tsw.2009.37

[27] Matteson, J.R., Stock, J.A., Hanna, M.K., et al. (2001) Medicolegal Aspects of Testicular Torsion. Urology, 57, 783-787. https://doi.org/10.1016/S0090-4295(00)01049-9

[28] Barbosa, J.A., Tiseo, B.C., Barayan, G.A., et al. (2013) Development and Initial Va- 
lidation of a Scoring System to Diagnose Testicular Torsion in Children. Journal of Urology, 189, 1859-1864. https://doi.org/10.1016/j.juro.2012.10.056

[29] Tengue, K., Kpatcha, T.M., Sewa, E., Adabra, K., Amavi, A.K., Sikpa, K., Botcho, G., Leloua, E., Anoukoum, T. and Dosseh, E. (2017) Management of Urological Emergencies in Togo. Uro' Andro, 1, 28-33. 